\title{
MisTERIO BIBLIOGRÁFICO CERVANTINO: El ROMANCERO UNIVERSAL DE MiguEL DE CERVANTES DE $1614^{\text {I }}$
}

\author{
José Manuel Lucía Megías \\ Universidad Complutense de Madrid \\ Asociación de Cervantistas
}

Title: Cervantes bibliographic mystery: Miguel de Cervantes'Romancero Universal of I6 I 4

\begin{abstract}
The Council of Castile kept a record of the procedures approved in each session since the i6th century. All of them are preserved in the National Historical Archive. One of these procedures was the granting of licenses and privileges for the printing of books. In the case of Cervantes works, the title indicated in this register corresponds to the title that should appear in your "petition memorials. All but one: when reviewing the granting of the licence for the Viaje del Parnaso (I6I4), the licence is granted to the Romancero universal. A new Cervantes bibliographical mystery, which is related to a Romancero universal by Alonso Jerónimo Salas Barbadillo, which was granted a printing licence in I $_{1}$ 3 , but which was never printed.
\end{abstract}

Key words: Cervantes. Viaje del Parnaso, Romancero Universal. Alonso Jerónimo Salas Barbadillo, Printing. Printing license.

La compleja maquinaria burocrática de la Monarquía Hispánica desde el siglo XVI ha generado miles y miles de documentos y registros de su tramitación. Por su propia naturaleza, y a pesar de los esfuerzos realizados en diferentes épocas, solo hemos conservado una pequeña muestra de todos los que se llegaron a entregar en los Consejos y el recorrido administrativo que realizaron. Un caso excepcional, por lo que conlleva de fuente de curiosas informaciones, tiene que ver con los expedientes de impresión de los libros publicados durante los últimos decenios del siglo XVI hasta principios del siglo XIX, que han sido estudiados en los últimos años por Fernando Bouza, feliz epígono de una larga lista de estudiosos que se han acercado al tema. ${ }^{2}$

${ }^{\mathrm{I}}$ Este trabajo se inscribe en el marco del Proyecto Parnaseo (Servidor Web de Literatura Española) (FFI20I4-5 I 78 I-P), concedido por el Ministerio de Economía y Competitividad. Agradezco a José Montero Reguera y Fermín de los Reyes su lectura y comentarios.

${ }^{2}$ Véase "Dásele licencia y privilegio". Don Quijote y la aprobación de libros en el Siglo de Oro, Madrid: Akal, 2012. 
El expediente de impresión necesita de dos documentos firmados por el autor (o por el cesionario de la obra para la que se pide licencia o el editor): por un lado el memorial de petición, y, por otro, el memorial de tasa, cuando ya está impreso el libro. Si el primero es necesario para comenzar con los trámites de impresión, el último lo será para poner a la venta el producto impreso. En los diferentes espacios de estas peticiones manuscritas, se dejaba constancia de los distintos procesos administrativos que se habían completado dentro del Consejo. Todas las peticiones que se presentaban ante el Consejo de Castilla, en el que funcionaban seis Escribanías de Cámara, se archivaban según dos sistemas según su naturaleza: por un lado, los "Pleitos de las Escribanías" y, por otro, los "Expedientillos de las Escribanías". Mientras de los primeros se llevaba un libro de matrícula, que permite conocer (casi) todo lo tramitado en estos años por cada una de las escribanías, los "expedientillos", que engloba aquellos asuntos de tramitación más breve y ágil, tan solo se ordenaban por meses y no se llevaba ningún libro de registro de sus trabajos. Por su propia naturaleza con escasa entidad documental y por las dificultades de conservar "toda" la ingente documentación que generaban las Escribanías de Cámara a lo largo del tiempo, ${ }^{3}$ muchos de estos documentos se han perdido. Tenemos constancia de su existencia, pero no así de su materialidad documental.

${ }^{3} \mathrm{Si}$ tenemos en cuenta la descripción que hace Santiago Agustín de Riol, lo sorprendente es la enorme cantidad de documentos que, en realidad, se han conservado: "Estos tenientes o arrendadores [de las Escribanías de Cámara del Consejo] procuran tener sus oficios en las calles del comercio, donde cuestan mucho los alquileres de las casas y necesitándolas grandes para la multitud de papeles y escritos, no solo los ponían en cuevas y desvanes, a donde la humedad, el polvo y los ratones los consumían o los hurtaban para tiendas y coheteros, sino que llevaban los pleitos y expedientes a casas de los arrabales, donde, mudando de mano, o se olvidaban o perdían”. Véase María Jesús Álvarez-Coca González, “La Cámara de Castilla: secretarías de Gracia y Justicia. Problemas archivísticos e investigación histórica”, en Johannes-Michel Scholz (ed.), El tercer poder: hacia una comprensión histórica de la justicia contemporánea en España, Fráncfort: Klostermann, I992, pp. I-32, cita pp. I 9-20. 
Son cuatro las Escribanías de Cámara ${ }^{4}$ que están implicadas en los expedientes de impresión de las obras cervantinas:

I. Escribanía de Cámara de Pinilla: Miguel de Ondarza Zavala: La Galatea (I585).

2. Escribanía de Cámara de Ayala: Juan Gallo de Andrada: Don Quijote de la Mancha (i6os).

3. Escribanía de Vicario: Hernando Vallejo: Novelas ejemplares (1613), Viaje del Parnaso (1614), Don Quijote (I6I5) y Ocho comedias y entremeses (I6I5).

4. Escribanía de Carranza: Jerónimo Núñez de León: Persiles y Sigismun$d a(1617)$.

De los siete memoriales de petición que solicitaron Miguel de Cervantes y Catalina de Salazar para la impresión de sus libros, solo se ha conservado el de la primera parte del Quijote, que fue asignado a la Escribanía de Cámara de Ayala, al escribano Juan Gallo de Andrada (entra en el Consejo en Valladolid el 20 de julio de 1604) y que fue dado a conocer por Fernando Bouza y Francisco Rico en el 2008..$^{5}$ El documento de tan solo un folio ${ }^{6}$ es una mina de noticias y de curiosidades: por un lado, permite conocer la

${ }^{4}$ Las Escribanías de Cámara se conocen con el nombre del último de sus escribanos, cuando dejaron de existir en i834. Gracias a la Memoria de los Escribanos de Cámara que ha babido en el Real Consejo de Castilla y sus sucesores, que se conserva en el AHN, que puede ser completado por los libros de Consejos 270 I, 33 I I y 333 I, tal y como se indica en PARES (http://pares.mcu.es/), es posible conocer, aunque no en su precisión cronológica, los escribanos que pertenecieron a cada escribanía.

${ }^{5} \mathrm{AHN}$ : CONSEJOS,44826,EXP. I.

${ }^{6}$ Además de poder consultarse una reproducción facsímil en el citado libro de Fernando Bouza, el documento está digitalizado en el portal PARES del Ministerio de Cultura y ha sido magníficamente reproducido en el libro Autógrafos de Miguel de Cervantes Saavedra, Madrid: Círculo científico, 2015. 
aprobación firmada por el cronista Antonio de Herrera (fechada el i I de septiembre de 1604), que no se había impreso entre los preliminares legales del libro; por otro, no dejó de sorprender el título inicial con el que se solicitó la licencia y privilegio, que no fue el último impreso: El ingenioso hidalgo de la Mancha; y, por último, a pesar de que la petición esté firmada por Miguel de Cervantes, no fue escrita de su puño y letra: el librero Francisco de Robles es el que solicitó la licencia y privilegio de impresión de la obra cervantina, con todas las implicaciones sobre su estrecha relación en su génesis, que sigue siendo uno de los capítulos más apasionantes de los estudios cervantinos y quijotescos. ${ }^{7}$

En cambio, no hemos conservado ninguno de los memoriales de tasa de las obras cervantinas, aunque la resolución del Consejo sí que termina siendo impresa entre los preliminares legales de cada uno de los libros, así como las licencias de impresión. De las que se concedieron a Cervantes, solo se ha conservado la de la primera parte del Quijote, en el cedulario del escribano Juan Gallo de Andrada, que fue dada a conocer por Marta Cuartas Ribero en el 2004. ${ }^{8}$

La comparación de los títulos que aparecen en los preliminares legales en las obras cervantinas -que dejan constancia de algunos detalles de la documentación manuscrita perdida-, y el que se indica en la portada, permite conocer una curiosa variedad de posibilidades, que ha sido ya remarcada por la crítica, y que, de nuevo, destaca la importancia del librero (o el poseedor de la licencia) a la hora de tomar las últimas decisiones de la difusión de una obra, como por ejemplo el título que aparecerá impreso en la porta$\mathrm{da}$, que puede ofrecer curiosas y pertinentes transformaciones. De acuerdo a estos datos contamos con las siguientes variantes:

${ }^{7}$ Para más detalles, véase José Manuel Lucía Megías, La plenitud de Cervantes. Una vida de papel, Madrid: EDAF, 2019.

${ }^{8} \mathrm{AHN}$ : CONSEJOS 4 I 056 , fol. 3 I $6 \mathrm{v}$. 
I. Primera parte de la Galatea dividida en seis libros (portada)

(a) Galatea (licencia)

(b) Los seis libros de Galatea (aprobación y tasa)

2. El ingenioso bidalgo don Quixote de la Mancha (portada)

(a) El ingenioso hidalgo de la Mancha (memorial de petición, aprobación, licencia y tasa)

3. Novelas exemplares (portada, aprobación de Fray Diego de Hortigosa y tasa)

(a) Doze novelas exemplares (aprobación del Doctor Cetina)

(b) Novelas exemplares de honestísimo entretenimiento9 (aprobación de Alonso Jerónimo de Salas Barbadillo, licencia y privilegio de Aragón)

4. Viage del Parnaso (portada, licencia, privilegio, fe de erratas y tasa)

5. Segunda parte del ingenioso cavallero don Quixote de la Mancha (portada, aprobación del licenciado Márquez Torres)

(a) Segunda parte de don Quixote de la Mancha (aprobación de José de Valdivieso y licencia/privilegio)

(b) Don Quixote de la Mancha segunda parte (tasa)

6. Ocho comedias y ocho entremeses nuevos, nunca representados (portada)

(a) Libro de comedias y entremeses (aprobación de José de Valdivieso)

${ }^{9} \mathrm{~A}$ cualquier lector de la época, este título lo relacionaría con el Honesto y agradable entretenimiento de damas y galanes de Giovanni Francesco Straparola, que, publicado en español en I 580, no dejó de reeditarse en estos años. 
(b) Ocho comedias y entremeses (suma del privilegio y tasa)

7. Los trabajos de Persiles y Sigismunda, historia septentrional (portada)

(a) Los trabajos de Persiles (aprobación y licencia)

(b) Historia de los trabajos de Persiles y Sigismunda (fe de erratas, tasa)

Como he indicado, de los "expedientillos" no se llevaba un libro de entrada, como sí se hacía de los pleitos. Pero el Consejo de Castilla sí que llevaba un "Libro donde se asientan en relación los despachos que se libran por el Consejo Real", que se conserva actualmente, como la mayoría de la documentación de los Consejos, en el Archivo Histórico Nacional. El primero es el que va desde el 5 de febrero de is93 al i de febrero de 1599 (CONSEJOS, L.640).

Gracias a esta documentación, podemos acercarnos, de manera indirecta, al memorial de petición hoy perdido de las distintas obras de Cervantes (dejando a un lado el Quijote, que hemos conservado), adentrarnos en algunos de sus detalles, como es el título con el que Cervantes presentó cada uno de sus libros, que, como no podía ser de otro modo, no se corresponde tanto con el título que aparece en portada $-\mathrm{y}$ que ha quedado marcado como si fuera la última voluntad del autor- como el que se indica en las licencias y privilegios impresos.

Estos "Libros de Justicia" ${ }^{\text {Io }}$ tienen siempre la misma estructura: el escribano indica el lugar y la fecha en la "se despacharon las provisiones y cédulas”, que fueron aprobadas por el Consejo y refrendadas por el secretario. Cada ítem, lleva a la izquierda la indicación de la persona o institución que lo solicita, y en la parte derecha, el nombre del Escribano de Cámara que lo presenta y lo ha tramitado.

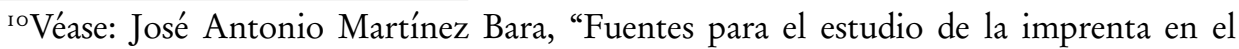
Archivo Histórico Nacional”, Cuadernos para la investigación en la Literatura Hispánica, 9 (I988), pp. 207-225. 
I. Quijote: Valladolid, 26 de septiembre de $1604^{11}$ [Cerbantes] Otra a Miguel de Cerbantes para que pueda imprimir un libro intitulado $E l$ ingenioso bidalgo de la mancha y privilegio por diez años [Gallo]

2. Novelas ejemplares: Madrid, 22 de noviembre de ${ }_{16} \mathrm{I}_{2}{ }^{\mathrm{I2}}$ [Cerbantes] Licencia a Miguel de Cerbantes para que pueda imprimir un libro intitulado Nobelas exemplares de honestísimo entretenimiento y previlegio por diez años [Olmedo ${ }^{13}$ ]

3. Quijote: Madrid, 30 de marzo de $1615^{14}$ [Çerbantes] Licencia a Miguel de Çerbantes Sahabedra para que pueda imprimir un libro intitulado La segunda parte de don quixote de la Mancha y previlegio por diez años [Vallejo]

4. Comedias y entremeses: Valladolid, 25 de julio de 16 I $5^{15}$ [Çervantes] Otra a Miguel de Cervantes Sahavedra para imprimir Ocho comedias con otros entremeses compuestas por él y nunca representadas [Vallejo]

I "En Valladolid a veinte y seis de setiembre de r604 años se despacharon las provesiones y cédulas siguientes firmadas de su Magestad refrendadas del secretario Juan de Amezqueta librada y señalada del Presidente y los del Consejo". AHN: CONSEJOS,L.642: fols. 38v$42 \mathrm{r}$.

I2 "En Madrid a veinte y dos de noviembre de mil y seiscientos y doze años se despacharon las provisiones y cédulas siguientes, firmadas de su Magestad y refrendadas del secretario Jorge de Tovar y Vadebarrama y libradas y señaladas del presente y los del Consejo en esta manera" (AHN: CONSEJOS,L.643, fols. 30 Ir-303r).

${ }^{13}$ Normalmente, suelen ser los escribanos titulares los que firmen los trámites de las Escribanías, pero, en su ausencia, podían firmar los "escribanos oficiales", de los que no se tiene constancia de sus nombres. Alonso vendría a sustituir a Hernando Vallejo, el titular de la escribanía en estos años. Agradezco a Eva Bernal, del Archivo Histórico Nacional, su comentario.

I4"En Madrid a 30 de março de mil y seiscientos y quince años se despacharon las provisiones y cédulas siguientes firmadas de su Magestad refrendadas del secretario Pedro de Contreras libradas y señaladas del presidente y los del Consejo" (AHN: CONSEJOS,L.644, fols. $33 \mathrm{v}-35 \mathrm{r}$ ).

is "En Valladolid a veinte y cinco de julio de mil y seiscientos y quinze años se despacharon las provisiones y cédulas siguientes firmadas de su Magestad y refrendadas del Secretario Pedro de Contreras libradas y señaladas del Presidentes y los del Consejo entrantes" (AHN: CONSEJOS,L.644, fols. 67r-69v). 
5. Persiles: San Lorenzo, 24 de septiembre de ${ }_{16}{ }_{1} 7^{16}$ [Salaçar] Otra a Catelina de Salaçar viuda de Miguel de Cervantes Sahavedra para que pueda imprimir un libro que el dicho su marido dejó compuesto intitulado Los trabajos de Persiles y previlegio por ı años [Leon]

Como es lógico, el título que se indica en la concesión, procedente del memorial de petición, se repite en las licencias y privilegios (que conocemos en su mayoría por ser impresos en los preliminares legales de las obras conservadas). A excepción de uno: si el Viaje del Parnaso, aparece tanto en la portada como en todos los trámites legales con este título, el único caso de uniformidad textual en la historia editorial de las obras cervantinas, en el Libro de Justicia, correspondiente a los documentos aprobados en Ventosilla el 18 de octubre de $1614{ }^{17}$, se indica lo siguiente:

[Çervantes] Licencia a Miguel de Cervantes Saabedra para que pueda imprimir un libro intitulado Romançero universal y previlegio por seis años [Vallejo]

Romancero universal. Todos los datos coinciden con el texto de la licencia y privilegio impreso en la edición del Viaje del Parnaso en i6 i 4:

Por cuanto por parte de vos, Miguel de Cervantes Saavedra, nos fue fecha relación que habíades compuesto un libro intitulado Viaje del Parnaso, de que hacíades presentación, y porque os había costado algún trabajo y ser curioso y deleitable, nos suplicasteis vos mandásemos dar licencia para le imprimir y privilegio por veinte años, o como la nuestra merced fuese; [...] Por la cual vos damos licencia y facultad para que, por tiempo y espacio de seis años cumplidos primeros siguientes, que corran y se cuenten desde el día

16“En San Lorenço el Real a veinte y cuatro de septiembre de mil y seiscientos y diez y seis años se despacharon las provisiones y cédulas siguientes firmadas de su Magestad refrendadas del escrivano Pedro de Contreras libradas y señaladas del Presidentes y los de su real Consejo (fols. AHN: CONSEJOS,L.644, I76r-178r)

${ }^{17}$ "En Ventosilla, a diez y ocho días del mes de otubre de mil y seis y catorce años, se despacharon las provisiones y cédulas siguientes firmadas de su Magestad y Refrendadas del Secretario Jorge de Tovar y Valderrama y libradas y señaladas del Presente y los del Consejo en esta manera" (AHN: CONSEJOS,L.643, fols. 466v-468r) 
de la fecha desta nuestra cédula en adelante, vos, o la persona que para ello vuestro poder hubiere, y no otra alguna, podáis imprimir y vender el dicho libro que desuso se hace mención. [...] Fecha en Ventosilla, a diez y ocho días del mes de octubre de mil y seiscientos y catorce años.

Yo, el rey.

Por mandado del Rey nuestro señor:

Jorge de Tovar. ${ }^{18}$

Romancero universal. ¿De dónde procede este título? ¿Cómo es posible que en el memorial de petición apareciera este título para un texto como el Viaje del Parnaso, que no está escrito en esta forma métrica, una de las más utilizadas por Cervantes y por la que era reconocido en su tiempo ${ }^{\text {I9 }}{ }^{1}$ Es posible entenderlo como un "error" del escribano, que, como hemos visto en el resto de las obras cervantinas, siempre refleja con exactitud el título que aparece en el memorial de petición? ¿Un cambio de esta naturaleza -que no es comparable a las variantes textuales documentadas- no conllevaría un problema legal, a la hora de conseguir la tasa final?

Una obra con el título de Romancero universal, en todo caso, no es la primera vez que se presentaba para su licencia tanto en el Consejo de Castilla como en el Consejo de Aragón, que será el primer espacio en que pedirá su autor, Alonso Jerónimo de Salas Barbadillo la licencia y privilegio. ${ }^{20}$

El 20 de octubre de 16 I 3 se le concede la licencia y privilegio de impresión de las cinco obras que había solicitado en su memorial de petición

${ }^{18}$ Cito por Miguel de Cervantes, Viaje del Parnaso y poesías sueltas, edición de José Montero Reguera y Fernando Romo Feito, con la colaboración de Macarena Cuiñas Gómez, Madrid: Real Academia Española, 2016, pp. 6-7.

${ }^{19}$ Véase José Domínguez Caparrós, Métrica de Cervantes, Alcalá de Henares: Centro de Estudios Cervantinos, 2002.

${ }^{20}$ Véase Jaime Moll, “Análisis editorial de las obras de Salas Barbadillo”, Silva: studia philologica in honorem Isaías Lerner, coord. por Isabel Lozano Renieblas, Juan Carlos Mercado, Madrid: Castalia, 200 I, pp. 47 I-478. Y como me recuerda Fermín de los Reyes, es época de edición de libros de romances: el librero Miguel Martínez obtiene la licencia de impresión del Romancero General el i i de enero de i6r4. Obra que se pone a la venta en mayo de este mismo año, impreso en el taller de Juan de la Cuesta. Quizás sea esta la razón de que, al final, Barbadillo no publicara su Romancero universal, dado que se le habían adelantado en esta apuesta comercial y editorial. 
unos meses antes: ${ }^{21}$ Corrección de vicios, El sagaz Estacio, La ingeniosa Elena (o sea la hija de Celestina), El caballero puntual y Romancero universal

El i6 de agosto de I6ı 3, el escribano de Cámara Villarroel fecha el memorial de petición que había presentado Salas Barbadillo al Consejo de Castilla: ${ }^{22}$

Muy poderoso señor Alonso Gerónimo de Salas Barbadillo digo que yo he compuesto cinco libros intitulados: Romancero universal, La injeniosa Helena, Boca de todas verdades, El sagaz Estacio y El cavallero puntual, todos muy provechosas a la república por su dotrina y moralidad. A V. Alteza pido y suplico mande se me dé su previlegio para podellos imprimir por tiempo y espacio de diez años que en ello reciviré merced. Alonso Gerónimo de Salas Barbadillo [rúbrica]

Se le encomienda el expediente de impresión a Martín Ferrán de Portocarrero. Las aprobaciones estarán firmadas por el Doctor Gutierre de Cetina (20 de diciembre de 1613) y por Fray Manuel de Espinosa (6 de enero de I6r4). La licencia y privilegio de cada una de las obras la aprobará el Consejo de Castilla el 2 I de enero de 16 I $4:{ }^{23}$

[Barbadillo] Otra a Gerónimo de Salas Barbadillo, vezino de Madrid, para que pueda imprimir un libro intitulado El cavallero puntual y previlegio por diez años [Vallejo].

[iden] Otra al mismo para que pueda imprimir un libro intitulado $E l$ sagaz Estacio y previlegio por diez años [iden]

${ }^{21}$ ACA, reg. 4895, fol. I 59v. Véase José Madurell Marimón, "Licencias reales para la impresión y venta de libros (I I I9-I 705)”, Revista de Archivos, Bibliotecas y Museos, LXXII (1964-65), p. i 85 .

${ }^{22}$ AHN: CONSEJOS, 44230.

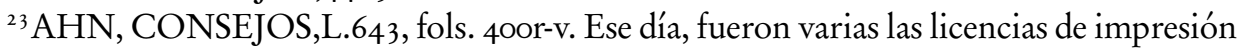
que aprobó el Consejo, además de las cinco a Salas Barbadillo: [I] Antonio de Rozas, La ciudad de Dios (Mármol); [2] Fray Antonio Ares, Diálogo de la naturaleza del hombre (traducido del latín) (León); [3] Fray Alonso Muñoz, Historia de cosas del Japón (iden); [4] Fray Cristóbal Márquez, Tesoro de ignorantes (Zabala); [5] Inca Garcilaso, Segunda parte de los Comentarios Reales (León); [6] Doctor D. Gutiérrez Márquez de Careaga, Perfecto clérigo (Zabala); [7] Fray Alonso de Bascones, Destierro de ignorancias y avisos de penitentes (León); [8] Fray Alonso Fernández, De Viris Illustribus Ordinis Predicatorum (Vallejo). 
[iden] Otra al mismo para imprimir otro libro intitulado Corrección de vicios y previlegio por diez años [iden]

[iden] Otra al mismo Gerónimo de Salas Barbadillo para que pueda imprimir un libro intitulado La ingeniosa Elena y previlegio por diez años [iden]

[iden] Otra al mismo para imprimir un libro intitulado Romancero universal y previlegio por diez años [iden].

Todas las obras fueron impresas a lo largo de i6I4 y i6 I $5^{24}$ (y el Estacio en 1620), ${ }^{25}$ a excepción del Romancero universal, la única de la que no conocemos edición impresa. Se da la circunstancia de que unos meses antes de solicitar la licencia para los nuevos libros, Salas Barbadillo presentó un memorial ante el Consejo de Castilla para que le devolvieran los originales de dos libros a los que no se habían concedido licencia de impresión: Romancero espiritual y Vida de San Francisco y Santos de su orden. ${ }^{26}$

$¿$ Es el Romancero universal, que ahora obtiene licencia, el mismo Romancero espiritual que no fue aprobado, y cuyo memorial de petición hemos perdido? ¿Qué relación puede haber entre el Romancero universal que presenta Salas Barbadillo en I6r 3 y el Romancero universal que le aprueban a Cervantes el i 8 de octubre de 16 I 4 ? ¿Le puso Cervantes al Viaje del Parnaso el título de Romancero universal en su memorial de petición de licencia, tal y como fue aprobado por el Consejo de Castilla? ¿Cómo es posible que este

${ }^{24[\mathrm{I}]}$ La ingeniosa Elena. Agora de nuevo ilustrada y corregida por su mismo autor, con tasa del I 2 de abril de I6 I4, Madrid, Antonio Rodríguez, I6 I4. [2] El cavallero puntual, con tasa fechada el 27 de agosto de I6 I4, Madrid, a costa del librero Simón de Vadillo, I6 I4. [3] Corrección de vicios, tasado el i6 de diciembre de I6 I4, Madrid, Miguel Martínez, I6 I 5.

${ }^{25}$ El sagaz Estacio, marido examinado, Madrid, Juan de la Cuesta, a costa del librero Juan de Frías, i620.

${ }^{26} \mathrm{AHN}$ : CONSEJOS,44230. "Muy poderoso Señor. Alonso Gerónimo de Salas Barbadillo vecino desta villa de Madrid digo que habiendo presentado ante V. Alteça dos libros intitulados el uno Romancero spiritual y el otro Vidas de Sant Francisco y Santos de su Orden y suplicado se me diese licencia para imprimillos se me á denegado A V. Alteça suplico mande que Diego de Villarroel scrivano de cámara en cuyo poder están me los vuelva que en ello reciviré merced. Alonso Gerónimo de Salas Barbadillo [rúbrica]”. El memorial entró en el Consejo el i 3 de febrero en I6 3 y la respuesta va a ser escueta y contundente: "No ha lugar". 
título no aparezca en ninguno de los preliminares legales, como hemos visto que es costumbre en la época, y que solo lo podamos rescatar en los libros de registro de los acuerdos del Consejo de Castilla, donde los escribanos suelen ser muy escrupulosos a la hora de reflejar los contenidos de los acuerdos tomados y refrendados por el Presidente?

¿Pudo existir, más allá de las referencias documentales que ahora se dan a la luz, una nueva obra cervantina con el título Romancero universal, género al que dedicó algunos de sus mejores versos y por el que fue conocido y reconocido en su época?

Un nuevo misterio bibliográfico cervantino.

recibido: mayo de 2019 aceptado: septiembre de 2019 